DOI: 10.18468/letras.2017v7n1.p59-85

\title{
DA PARCEIRA DEDICADA À “PERIGUETE”: SEXUALIDADE E IDENTIDADES DA MULHER EM CLAUDIA E TPM
}

\author{
Gabrielle Vívian Bittelbrun ${ }^{1}$
}

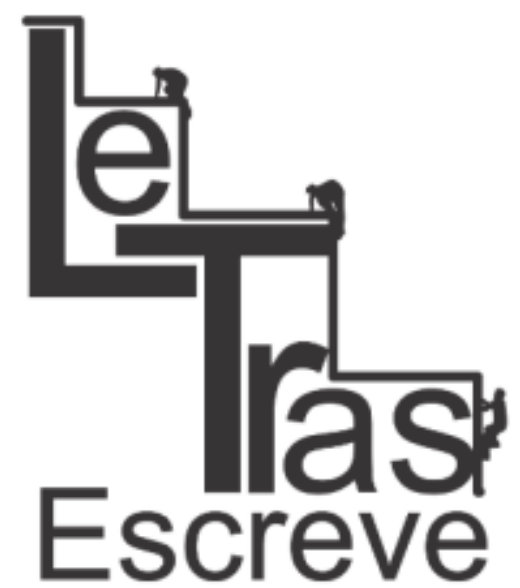

(ISSN 2238-8060)

RESUMO: Supõe-se que, comparando-se com décadas anteriores, as revistas femininas brasileiras do século 21 concentram discursos de uma liberação inédita no que tange à temática da sexualidade, até pela maior participação da mulher na sociedade e pelas inúmeras possibilidades de controle de fertilidade. No entanto, um olhar sobre matérias jornalísticas de Claudia e TPM - dois títulos que são referenciais no mercado do país - dá as pistas de normas remanescentes sobre o gênero feminino, referindo-se também a um regime de patriarcado. Assim, as edições trazem recomendações sobre a vida sexual e, conectada à ela, a vida amorosa, propondo como seduzir e atrair o parceiro, sempre sob a perspectiva da heterossexualidade. Apoiando-se em pesquisas como de McClintock (2010) e Funck (2014), acredita-se que exemplares entre 2012 e 2014 dos dois veículos em questão possam servir como um caminho para se avaliar a construção de diferenciações de gênero e a manutenção, ou não, de antigas atribuições. Acreditase que ao discorrer sobre a sexualidade da mulher, seja falando da parceira dedicada ou da "periguete", as revistas acabam por interpelar identidades, com sugestões de como ser, agir, parecer, o que requer uma discussão, também com o apoio de teóricos como Culler (1999) e Hall (2014).

Palavras-chave: Gênero. Revista feminina. Identidade. Sexualidade.

ABSTRACT: It is assumed that, compared with previous decades, the discourse found in Brazilian women's magazines of the 21st century is centered around an unprecedented liberation of sexuality, because of a greater participation of women in society, and a wide range of birth control possibilities. However, a look at Claudia and TPM - magazines that are benchmarks in the publishing market in Brazil - reveals traces of domination over women and of a patriarchal regime. Thus, the issues of these magazines advise women on sex life associated with love life, and teach readers how to seduce a partner - always from a heterosexual perspective. Research studies such as those by McClintock (2010) and Funck (2014) support the belief that the issues of the two above-mentioned magazines published between 2012 and 2014 can be used in the analysis of construction of gender difference and maintenance (or not) of former gender-related tasks. It

\footnotetext{
${ }^{1}$ Doutoranda pelo Programa de Pós-Graduação em Literatura da Universidade Federal de Santa Catarina (UFSC), Mestra em Jornalismo pela mesma instituição e Jornalista pela Universidade Estadual Paulista "Júlio de Mesquita Filho" (Unesp). Integra o Grupo de Pesquisa Núcleo de Literatura Brasileira Atual - Literatual - Estudos Feministas e PósColoniais de Narrativas da Contemporaneidade da UFSC. E-mail: gabrielle.bittelbrun @gmail.com.
}

https://periodicos.unifap.br/index.php/letras

Macapá, v. 7, n. I, Io semestre, 2017. 
is believed that when magazines generate discussion about women's sexuality, talking about the devoted partner or the "periguete" - a coloquial term near to "hoochie" -, they address identities, and put forward suggestions about how to be. This should be a matter for debate, referenced by theorists such as Culler (1999) and Hall (2014).

Keywords: Gender. Women's magazine. Identity. Sexuality.

\section{Introdução}

Ao folhear uma publicação feminina brasileira, é possível se deparar com mulheres que procuram variedade sexual e só buscam o sexo por prazer, sem a preocupação com relacionamentos estáveis. Ou ainda, podem-se encontrar recomendações do que fazer para manter o desejo sexual do parceiro ao longo do tempo, no tradicional

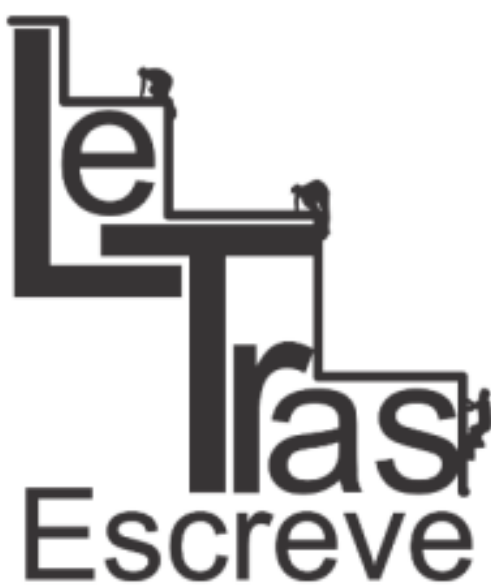

(ISSN 2238-8060) estilo passo a passo. Caberá ao público leitor - a saber, composto majoritariamente por mulheres - concordar com um direcionamento ou com outro, de acordo com as próprias experiências e visão de mundo.

Em uma breve ida à banca, então, passando pelas páginas de Claudia e TPM, duas revistas voltadas para as mulheres e que compartilham um setor de leitores com uma determinada faixa etária e poder aquisitivo ${ }^{2}$, nota-se que não há um consenso quando trata da temática amorosa e da sexualidade da mulher, de modo que se fala de uma liberação sexual, ao mesmo tempo em que ainda são propostas dicas de como se comportar entre quatro paredes.

Nesse sentido, com suas variadas e até divergentes propostas de "certo" e "errado", os títulos contribuem para processos de identi-

\footnotetext{
${ }^{2}$ As duas publicações têm como alvo as classes A e B e um público composto entre $91 \%$ e $92 \%$ por mulheres. Embora não se tenha encontrado a mesma discriminação de público nos dois títulos, nota-se que eles compartilham uma certa faixa de público-alvo. Em Claudia, 44\% das leitoras têm entre 25 e 44 anos (ABRIL, 2015), enquanto 69\% das leitoras de TPM têm entre 26 e 45 anos (TRIP, 2015). Observa-se ainda que Claudia conta com um expressivo público mais velho, 34\% são de leitores acima de 50 anos, talvez até pelo tempo de circulação da revista. No caso de TPM, apenas $18 \%$ dos leitores têm idade superior a 45 anos.
} 


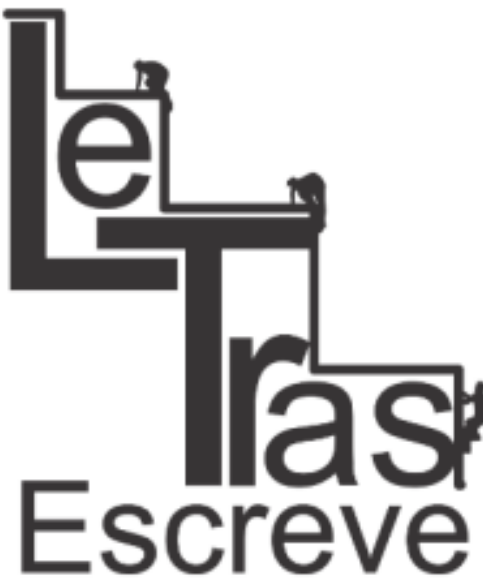

(ISSN 2238-8060)

ficação transitórios e variáveis, seguindo a tendência atual exposta por Hall (2014). Pretende-se avaliar como algumas dessas descontinuidades são apresentadas em discursos atuais sobre sexualidade em revistas e quais podem ser os efeitos na proposição de identidades, questionando ainda sobre as atribuições ao gênero feminino, imersas na lógica do patriarcado.

Ao mesmo tempo, leva-se em conta que, ao não problematizar suas recomendações e as bases sobre as quais se estabelecem as convenções, as revistas sugerem uma tranquilidade e até passam a ideia de uma estabilidade de sugestões que não se confirma na prática e nem reflete a complexidade do contexto social, o que pode aumentar tanto o caráter normativo das enunciações como até a inquietação por parte do público, incapaz de seguir tudo o que é destacado.

Enfim, visando a essas discussões que pretendem colocar luz especialmente no que se refere a gênero ${ }^{3}$, sexualidade e proposição de identidades, destaca-se quatro matérias jornalísticas ${ }^{4}$, de edições entre 2012 e 2014 de TPM e Claudia, que abordam amor e sexo e se fazem relevantes como produtos de comunicação de massa.

Revista feminina mais antiga em circulação no Brasil a manter o mesmo formato, Claudia firmou-se sobre a proposta de liberação do gênero, exaltando ideais como da mulher no mercado de trabalho ou defendendo métodos contraceptivos, posicionamentos considerados subversivos nos anos após seu lançamento na década de 1960.

\footnotetext{
${ }^{3}$ As mencionadas revistas falam para um público denominado feminino, como se existisse uma categoria uniforme "mulheres", que compartilharia interesses, angústias. Admite, no entanto, a análise a esses termos de forma crítica. Afinal, seguindo a linha de autoras feministas como Lauretis (1994), entre outras, não existe esse grupo "mulheres" como um todo coerente e completo. Tratam-se de construções sociais, discursivas, carregadas de fissuras de modo que, nessa constante reiteração, há a possibilidade de mudança.

${ }^{4} \mathrm{~A}$ intenção foi escolher matérias que dedicassem ao menos duas páginas para a abordagem dos temas e pudessem ser consideradas referenciais no tratamento dos assuntos amor e sexo, recebendo chamadas de capa ou destaques no índice.
} 


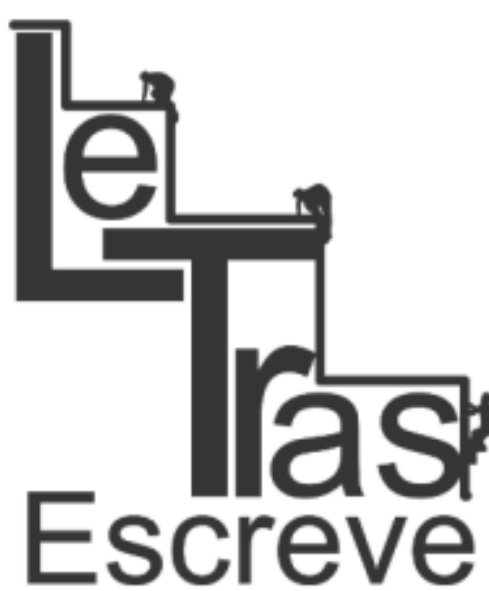

(ISSN 2238-8060)
Ao mesmo tempo, a revista não deixaria de trazer dicas de um suposto universo feminino, trazendo temas como decoração, culinária, moda. O próprio nome do veículo propõe uma proximidade e amizade com a leitora, como se ele conhecesse e soubesse solucionar os problemas do público. Hoje, tem uma tiragem de cerca de 379 mil exemplares mensais (ABRIL, 2015).

Por outro lado, a jovem TPM, lançada em 2001, surgiu com o indicativo de se contrapor aos estereótipos relacionados à figura feminina. Para tanto, a revista se valeria de enfoques diferenciados e assuntos como violência sexual e feminismo. "Trip Para as Mulheres" sugere um veículo destinado a uma categoria que encontraria naquelas páginas matérias que se distanciariam daquelas encontradas na maior parte de suas concorrentes. A revista contemplaria as mulheres do "mundo real", como se ressalta em inúmeras capas com personalidades sem maquiagem ou sem intensa produção de figurino ${ }^{5}$, como é reforçado também no site da Editora (TRIP, 2015). TPM chegou a contar com 80 mil exemplares mensais mas anunciou que, a partir de 2017, lançará apenas edições digitais.

De qualquer modo, com suas inúmeras sugestões, tais como os temas amor e sexo que ocupariam posição central, a revista não deixaria justamente de propor o que seria essa mulher moderna ou essa mulher real, incitando a comportamentos e a visões das leitoras sobre si mesmas, o que merece ser debatido. Como propõe Culler (1999, p. 111), "hoje, esse conceito de identidade é sustentado pelos

\footnotetext{
${ }^{5} \mathrm{Na}$ maioria das edições, a revista traz duas opções de capa, que costumam variar em ângulo ou até em personagens e cenários. A edição de agosto de 2013, por exemplo, ousou ao trazer, na capa, a atriz Alice Braga, com maquiagem, figurino e penteado elaborados, junto com chamadas como "Fique mais magra que a sua amiga" e "274 roupas incríveis para virar outra pessoa". Na contracapa, Alice aparece com o cabelo mais natural, sem penteado, e com maquiagem e roupas mais leves, acompanhada da frase "Para quê mentir?", em um claro questionamento em relação ao que é colocado em destaque nas concorrentes.
} 
filmes, pela televisão e por uma ampla gama de discursos, cujos cenários nos dizem o que é ser uma pessoa, um homem ou uma muIher".

\section{1. $O$ sagrado ventre: a origem}

Se, segundo Wolff (2011, p.114), o corpo feminino deve ser visto como um "constructo social, ideológico e histórico", considerar a sexualidade da mulher na atualidade, como um conjunto de efeitos sobre esses corpos e sobre a formação de identidades, é observar também relações sociais e atribuições antigas e novas associadas ao gênero feminino. Nesse processo, é preciso olhar ainda para a relação entre essas atribuições e o patriarcado, como uma "tecnologia moral", nas palavras de Diniz (2014, p. 11) que trabalha por meio de instituições como a família, a escola, os meios de comunicação.

Enfim, nessas discussões, faz-se necessário um breve panorama histórico. Retomando-se McClintock (2010, p. 54), tem-se que, na era das conquistas coloniais, as mulheres eram admitidas como propriedades masculinas e suas contribuições eram diminuídas, em uma forma de compensação por parte dos homens, inclusive pela incapacidade masculina de comprovar de imediato a verdadeira origem de sua prole - privilégio exclusivo das mães.

Outro ponto que merece atenção, naquela fase, é o controle da sexualidade feminina que foi parte imprescindível no processo civilizatório das colônias. Como detalhou Priore (1993), no período colonial brasileiro, o discurso normatizador, que tinha como grandes aliados os saberes médico e religioso, objetivava valorizar o casamento e, dentro dele, a função considerada "natural" da maternidade, a fim de converter as populações femininas a um modelo de compor- 


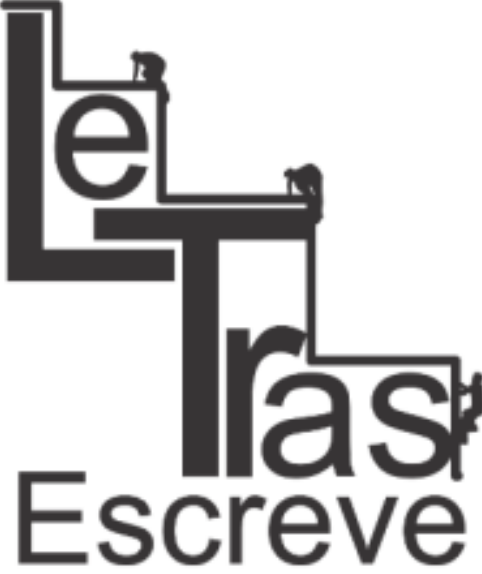

(ISSN 2238-8060)

tamento que fosse útil ao projeto civilizatório. Stolke (2006, p. 26), complementa que, enquanto o status social fundamenta-se no nascimento, no sangue, na descendência, em vez de méritos ou aquisições socioeconômicas, torna-se "decisivo para os homens em suas disputas por honrarias sociais as mulheres e o controle de sua sexualidade".

Afinal, ao mesmo tempo em que garantiria o aumento da população da colônia, a figura da "santa-mãezinha", dedicada ao âmbito doméstico, aos filhos e ao marido, evitaria qualquer possibilidade de desordem e contravenção. Além de serem vistas como seres inferiores e débeis, dependendo de cuidado e vigilância masculinos e carregando corpos cheios de mistérios que, até então, não tinham sido esclarecidos pela medicina, as mulheres seriam a via para a queda e perversão dos homens. A sexualidade feminina precisaria ser controlada à medida em que seria a porta de entrada para a degenerescência, para a propagação de doenças e até para a mestiçagem que ameaçaria a nobre "raça imperial".

O fato é que, seja pela via da paranoia dos homens, a que se referiu McClintock (2010), ou pelos caminhos do adestramento feminino previsto pela colonização, debatida por Priore (1993), consolidou-se o modelo da mulher recatada e mãe que atravessaria os séculos, servindo de elo de transmissão dos valores da Igreja e de instrumento para o povoamento da colônia. A própria lógica do patriarcado confluiria para isso, pois a encarnação do gênero tornaria os sujeitos "superfícies naturalizadas pela ilusão ontológica do binarismo sexual com finalidades reprodutivas", de acordo com Diniz (2014, p. 12). Como ainda sentencia a referida autora, na multiplicidade de interpelações da moral patriarcal, uma estará no centro: a figura da potencial reprodutora asilada em uma família.

https://periodicos.unifap.br/index.php/letras

Macapá, v. 7, n. I, Io semestre, 2017. 
Desse modo, a exaltação da figura da "mãe", ser quase celestial, seria uma das estratégias para a manutenção das proposições que confluíram para o controle da sexualidade feminina e para a manutenção do poder patriarcal. No entanto, se o poder se vale de suas próprias ferramentas para mascarar seu caráter coercitivo, ele não deixa de lançar mão de recursos repressores.

Portanto, as mulheres que mantinham relações admitidas como ilegítimas, estando fora da instituição do casamento, foram julgadas no rigor dos preconceitos desde a era colonial. Como toda normalidade se estabelece pela delimitação de seu desvio, a figura da valorizada "mãezinha" e "exemplar esposa", com seus padrões ideais de comportamento, construiu-se também com base no seu oposto, a "mulher sem qualidades", a "devassa" que seria excluída e demonizada socialmente. Com frequência, o estigma, estendido também às solteiras e às infecundas, viria associado a questões de raça e de classe, à medida em que essas desqualificadas seriam, em muitos casos, também aquelas de classes baixas, negras, mulatas ou índias, condenadas também como pivôs da indesejada miscigenação. Preocupação dos poderes institucionais, elas carregariam um pesado (ISSN 2238-8060)

julgamento moral, por irem contra a sua suposta natureza de mãe, e não colocarem seus corpos a serviço da sociedade patriarcal e do projeto colonizador. Formou-se, então, a discriminação das mulheres entre aquelas que viviam em pecado, que seriam símbolo de decadência e contravenção e as virtuosas.

Da era colonial aos séculos que se seguiriam, os sermões dominicais pregavam que haveria salvação para as perdidas, porém, a Igreja contribuiu para reiterar a suposta inferioridade da natureza feminina e a distinção e depreciação dentro do grupo "mulheres". Como se sugeriu nas recomendações às famílias de moças até mea- 


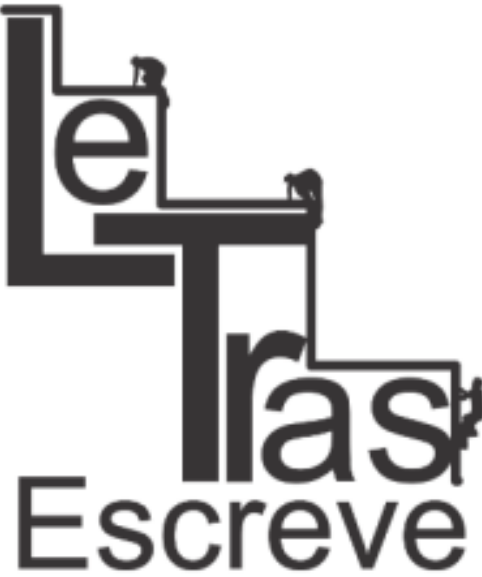

(ISSN 2238-8060)

dos do século 1960, era necessário uma vigilância constante sobre corpos e práticas, pois, com um simples descuido, elas poderiam se "desvirtuar". Para se evitar essa decadência, se faziam necessários a atenção das figuras religiosas, o apoio dos médicos e a própria determinação feminina, voltando-se completamente para o seio do lar, em obediência ao seu marido e à família.

Considerando-se esse breve panorama geral, nota-se que o século 21 chegaria com uma conhecida liberação dos costumes para as mulheres, impulsionada também pela propagação dos exercícios físicos, pela maior participação da mulher na sociedade e pela popularização dos métodos contraceptivos, enfraquecendo a ligação entre sexualidade e reprodução. No entanto, na nova época, não se extinguiria por completo o controle sobre os corpos femininos na sociedade. $O$ uso da mão punitiva para a governança do gênero, como bem expôs Diniz (2014, p. 18), seria manifestado claramente pelas leis que ameaçam de prisão as mulheres que abortam. A obsessão com a formação de famílias, atualiza-se, dessa maneira, mantendo os corpos femininos sob controle e ainda execrando mulheres ao grupo de "pecadoras".

Como complementa Swain (2014, p. 39), "o patriarcado não cessa de discorrer sobre mulheres, seus corpos, suas mentes, destilando 'verdades' absolutas a seu respeito". Assim, sendo mulheres no social ou fêmeas no biológico, esses "corpos-em-mulher fixam uma identidade fictícia nas quais se imbricam as injunções do amor e da sexualidade", como ainda destaca a autora, o que, como não poderia deixar de ser, seria manifestado também em discursos de revistas atuais.

https://periodicos.unifap.br/index.php/letras

Macapá, v. 7, n. I, Io semestre, 2017. 


\section{Sedutora e dedicada parceira em Claudia}

Se, considerando-se ainda o que expôs Swain (2014, p. 40), três dispositivos seriam ativados na sustentação da diferença sexual entre homens e mulheres, o dispositivo amoroso, o da sexualidade e o da violência ${ }^{6}$, em Claudia, esses dois últimos seriam inseparáveis nas matérias jornalísticas.

Ressalta-se que o dispositivo amoroso solidifica a imagem da "verdadeira mulher", responsável pelos laços familiares, pela educação dos filhos e pela manutenção do casamento, enfim, a figura doce, amável, devotada. Ainda seguindo o que propõe Swain (2014, p. 41), o amor seria proposto como fundamento identitário das mulheres e, por isso, elas estariam prontas para se sacrificar e viver no esquecimento de si em prol do outro. Já o dispositivo da sexualidade cria a necessidade absoluta do sexo e se refere principalmente ao masculino, que estaria "naturalmente" ligado ao sexo, assim como a mulher estaria à área amorosa.

Tais divisões ficam bem evidentes ao se olhar a matéria Ele só pensa em dormir (ZIEMKIEWICZ, 2013), de Claudia, que trata da falta

de apetite sexual masculino. O texto se inicia assim: "Uma tentativa de seduzir, duas, três... (...). A essa altura, a mulher já compôs várias teses para explicar o desinteresse: 'Estou menos atraente'; 'Devo andar meio chata'; 'Ele tem outra'”. Nessa sequência, a revista acaba por propor, inclusive, o que a mulher deve pensar.

De qualquer forma, para conseguir resolver esses problemas,

\footnotetext{
${ }^{6}$ Lembrando que se trata apenas de uma separação heurística, uma vez que todos estão imbricados na instituição patriarcal, Swain (2014, p. 40) destaca os seguintes dispositivos: a) dispositivo amoroso, que é a rede social de convencimento das mulheres em relação aos papéis que lhes são atribuídos tradicionalmente; b) o dispositivo da sexualidade, que faz das mulheres um corpo sexuado; e c) dispositivo da violência, que atua materialmente com a ameaça, o estupro, o sequestro, o assassinato, o incesto, a pedofilia e toda forma de intimidação àquelas que ousam desafiar seu controle.
}

https://periodicos.unifap.br/index.php/letras

Macapá, v. 7, n. I, Io semestre, 2017. 


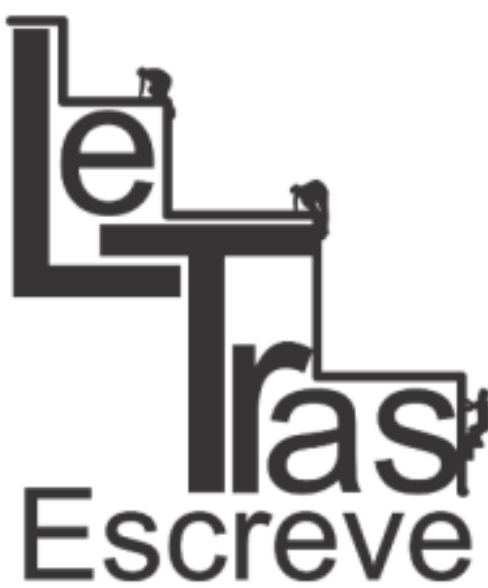

(ISSN 2238-8060)

a leitora deve contar com a "ajuda" da revista, que traz especialistas falando da dificuldade que os homens ainda têm de dizer "não" para o sexo pois, desde cedo "o menino incorpora a ideia de que deve ser forte e dominador - e a iniciativa das relações é, inapelavelmente, dele". Como ainda retrata Claudia, ele tem necessidade de se sentir o provedor da família e, "se a mulher não acolhe isso, é possível que se instale nele a sensação de enfraquecimento. E, diante desse quadro, nem uma lingerie provocante dará jeito".

Apesar de ameaçar, então, uma discussão quanto às atribuições de gênero, como o papel social masculino de ser o provedor da família, a revista acaba por reforçar as diferenciações ao propor que, caso a mulher viva uma situação desse tipo, ela "acolha" o homem e avalie quais os tópicos que podem estar preocupando o parceiro. A figura feminina aparece, então, como a cuidadora e ainda a responsável pelo acionamento da máxima potência masculina na cama; com suas táticas, ela será a chave de reestabelecimento da suposta ligação "natural" do homem ao sexo. Cabe a ela, e somente a ela, ajudar a resolver os problemas e "acordar", inclusive sexualmente, o homem que dorme na primeira foto da matéria em questão.

É necessário ressaltar, nesse ponto, não só a delimitação bem precisa de uma situação, almejando-se uma identificação por parte do público, reforçada ainda por um tom de conversa e aproximação, como ainda a construção da mulher quase como uma feiticeira, que pode se valer de seus truques para seduzir o parceiro, como vestir uma "lingerie provocante". Nesse aspecto, nota-se a antiga associação da mulher e pecado, enfim, como figura que seria capaz de "desviar" o homem do percurso pretendido.

No entanto, para que esses truques, feitiços supostamente inatos das mulheres sejam eficazes, acaba sendo necessário o apoio 


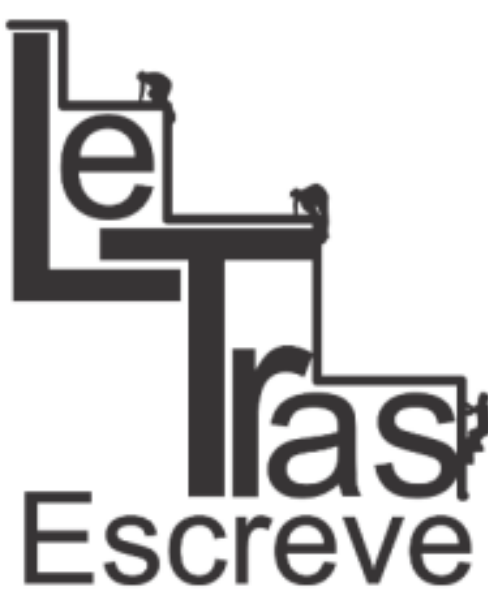

(ISSN 2238-8060)

da revista, que trará o saber especializado no "plano de ação para reacender o desejo". Assim, o que se consolidou como natureza feminina e o respeitado patamar da ciência se aliariam nesse ritual de conquista, em que cada um dos personagens ocuparia seu papel.

A própria capa dessa edição de abril de 2013, protagonizada pela apresentadora Angélica, sorrindo, em uma pose altiva, acompanhada pela chamada em letras garrafais "faça acontecer" já reitera a responsabilidade da mulher também no quesito sexualidade. Essa tônica alivia o peso masculino em qualquer fracasso, relegando-se a ela a necessidade de "ação" e, mais ainda, a culpa caso algo não ocorra conforme o esperado. E, com a descrição minuciosa de uma situação hipotética, a revista constrói até o que seria o tal "esperado", no caso, a mulher lançar mão de recursos para seduzir e ser correspondida com o desejo sexual masculino, tendo-se como obrigatoriedade o sexo.

A matéria em questão traz ainda um passo a passo para a muIher, com recomendações de mudar a rotina; observar a frequência do sexo; tentar outras modalidades no ato sexual; consultar outros especialistas da área e, sob nenhuma hipótese, fazer julgamentos, já que "homens têm vergonha de falar das próprias dificuldades" (ZIEMKIEWICZ, 2013). Se a mulher seguir esse guia e nem assim tiver jeito, pode ser o caso, então, como ressalta o veículo, de abrir espaço para um novo par, afinal, a atração pode ter acabado, ele pode ter se ligado a outras parceiras ou, inclusive, mudado a orientação sexual como se esse fosse um dos raros motivos que justificasse a mulher desistir de seu "plano de ação".

Enfim, reitera-se a obrigatoriedade do sexo como uma das principais vias para a constituição identitária e base do relacionamento amoroso. Por outro lado, vale observar que tanto nas matérias de 


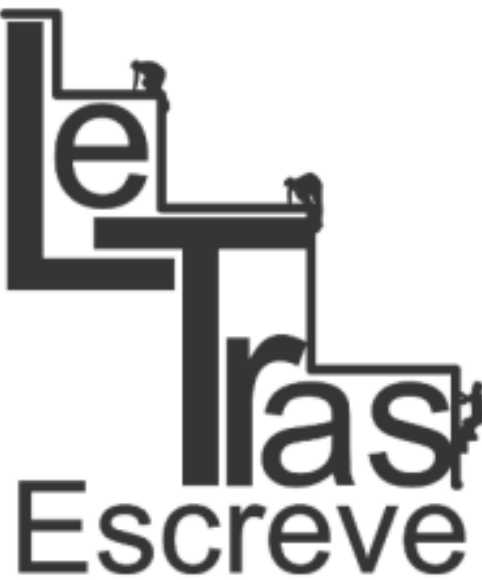

(ISSN 2238-8060)

Claudia como nas de TPM que serão analisadas, admite-se a figura do "parceiro", em um avanço na admissão de relacionamentos "não formalizados" pelo casamento, comparando-se com a década de 1960, quando Claudia claramente dava dicas que deveriam ser aplicadas com o "marido", impregnadas de um puritanismo muito maior (COSTA, 2009). Mesmo assim, nas edições atuais, tem-se que, antes de trocar o par, a mulher deve esgotar todas as possibilidades elencadas, em uma evidente valorização dos relacionamentos estáveis. Além disso, acompanhando ainda a reiteração das diferenciações entre homens e mulheres e a obrigatoriedade do sexo, a heterossexualidade será a norma nas relações amorosas e sexuais nas duas revistas, como se não houvesse outra maneira de ter um par.

Os mesmos direcionamentos de Ele só pensa em dormir (ZIEMKIEWICZ, 2013) são encontrados na matéria Não basta durar! Tem que ser muito bom (D'ERCOLE; KRANZ, 2014, p. 178-180), também de Claudia $^{7}$. A ilustração da matéria, com uma mulher no colo de um homem sorrindo e recebendo um beijo, em um figurino e envelhecimento gráfico que remetem a uma outra época, talvez da década de 1920, já dá a dica de que o que será trazido não é algo muito inovador. A própria perspectiva da foto reitera uma submissão feminina, à medida em que a mulher não só está sustentada corporalmente pelo homem, com os pés suspensos no seu colo, como ainda parece feliz diante da iniciativa amorosa dele, certamente pelo beijo e pelo buquê de flores, depositado sobre as pernas dela. Além disso, as mãos da mulher no próprio peito, como se estivesse suspirando, remetem mais uma vez à ligação feminina com o lado emocional, algo que seria intrínseco à sua natureza. Já o homem se associa ao sexo, à medi-

\footnotetext{
${ }^{7}$ Esse exemplar de outubro de 2014 de Claudia é protagonizado pela jornalista Fátima Bernardes que, com figurino e maquiagem de festa, em uma produção característica desse espaço, enuncia que se trata de uma edição de aniversário, mensagem reforçada pelas palavras, em letras garrafais: "É festa!".
}

https://periodicos.unifap.br/index.php/letras

Macapá, v. 7, n. I, Io semestre, 2017. 


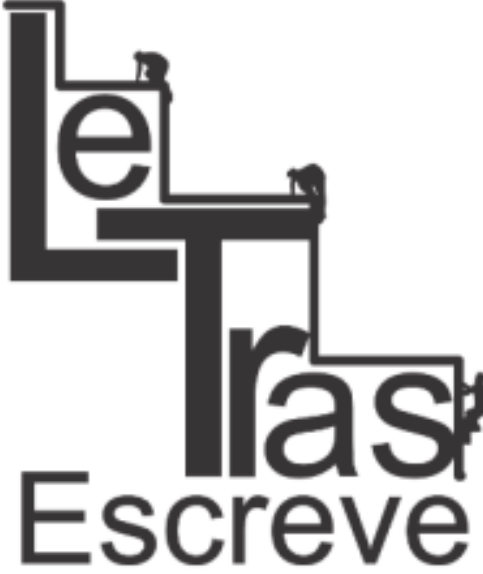

(ISSN 2238-8060)

da em que segura a cintura da parceira e carrega um sorriso aparentemente malicioso.

Na matéria, a publicação aborda questões para "driblar as dificuldades da vida a dois e manter a saúde no casamento", como diz a linha de apoio, em um enfoque que novamente alia o sexual ao emocional. De um modo geral, as dicas de especialistas - um psicólogo, um psiquiatra e um psicoterapeuta - de como manter a confiança e a lealdade no relacionamento, não se priorizando, por exemplo a carreira profissional e nem se tentando mudar o parceiro, deveriam, aparentemente, ser compartilhadas por homens e mulheres. Não há, então, atribuições claras a um e outro, apontando que os dois precisam caminhar na mesma direção e fortalecer laços, o que contaria pontos no que se refere a uma proposta de igualdade de gênero. Porém, além da ilustração que aponta o que seria "típico" a um e outro, o próprio título da matéria sugere que a relação estável é algo a ser almejado e a manutenção da saúde do relacionamento é uma obrigação.

Acrescenta-se a isso o fato de que, na segunda parte da matéria, elencam-se recomendações relacionadas ao romance e ao sexo com as delimitações de gênero voltando a ser bem destacadas. As próprias sugestões dos especialistas convergem para isso, propondose que a mulher use um vestido sexy e se empenhe para querer mais sexo o que, para o homem, seria "mais simples". Em troca, o parceiro também deve se dedicar, oferecendo mais romantismo, dispondo-se, inclusive, a andar de mãos dadas. De um modo geral, a mensagem final transmitida é que os dois precisam entender os limites e a vontade do outro para entrarem em sintonia.

Embora sigam o senso comum, de associação do feminino e das emoções, o que não deixa de contribuir para se relegar à mulher

https://periodicos.unifap.br/index.php/letras

Macapá, v. 7, n. I, Iㅇ semestre, 2017. 


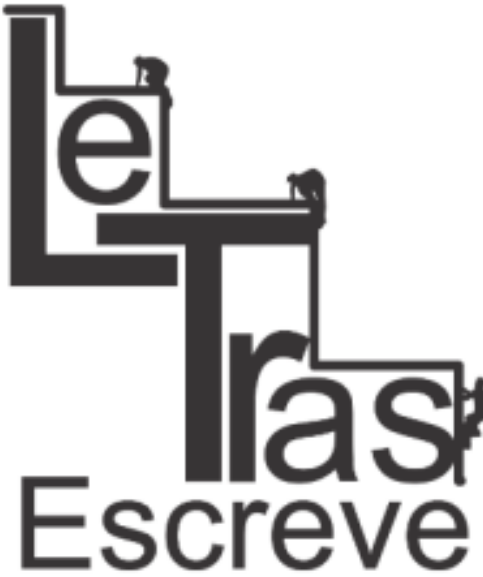

(ISSN 2238-8060)

uma posição fragilizada, como representantes do meio científico, os especialistas que são fontes da matéria certamente se valeram dos próprios aspectos biológicos quando dão suas indicações. No entanto, nesse ponto, vale lembrar Fausto-Sterling (2002), para quem a sexualidade é um fator somático criado por um efeito cultural. Seguindo o que coloca a autora, o próprio conhecimento científico não está livre dos contextos sociais e de histórias específicas e carregam suas marcas. Assim, esses supostos "desejos" de que falam os especialistas em Claudia não deixam de passar por valorações historicamente construídas sob a lógica do patriarcado. É como se as emoções e o romantismo fizessem parte dessas "vontades" ou "limites" do pacote "santa-mãe" e "zelosa esposa" que acompanharia toda e qualquer mulher, como propõe a publicação, enquanto o homem, símbolo da razão, precisasse de um esforço extra para dar mais vazão a questões dos sentimentos, que estariam aquém de seus instintos. Esse pacote fechado que a revista expõe para que a leitora se identifique acaba restringindo maciçamente as formas de ser e agir, engessando os sujeitos sob esses rótulos constantemente reiterados. Seria como se, seguindo essa voz de autoridade das revistas, com o apoio do saber científico, não fossem possíveis outras formas de ser homem e de ser mulher.

\section{Ninfoplastia e as periguetes em TPM}

Na lombada do exemplar de setembro de 2014 de TPM, uma pergunta inusitada: "A xoxota é o novo pinto?". Em edição especial "sobre a vagina", a revista pretende questionar a superexposição do órgão feminino que, talvez, até roubasse a posição tradicionalmente ocupada pela genitália masculina, historicamente carregada de um

https://periodicos.unifap.br/index.php/letras

Macapá, v. 7, n. I, Io semestre, 2017. 


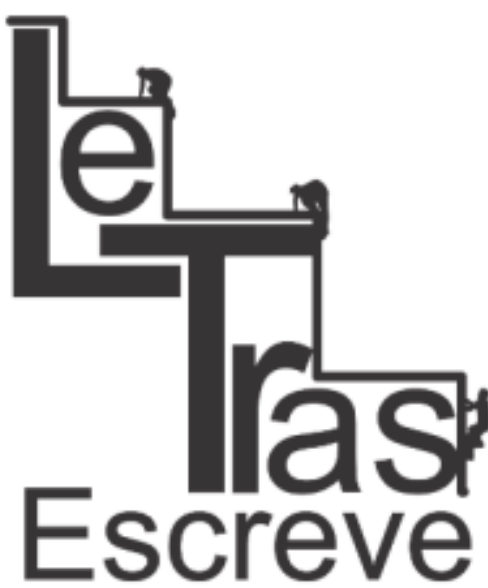

(ISSN 2238-8060)

imaginário de virtudes sociais e, em última instância, de poder. Já na primeira página, a revista indaga por quê a vagina ainda seria um grande tabu. De fato, a publicação que diz "mexer com os padrões da mídia feminina no país" (TRIP, 2015) traz uma abordagem de sexualidade feminina que causa impacto desde a capa. E isso não só por termos como "xoxota", dificilmente encontrados em outros veículos do setor, como pela própria pose da atriz Deborah Secco que encara o público, enquanto está com a mão na própria vagina - vestida por uma cueca -, sugerindo-se a masturbação, em um distanciamento das capas convencionais desse tipo de publicação, conhecidas por trazerem celebridades bem produzidas e em poses discretas, focando principalmente o rosto.

Certamente, tais recursos são usados não apenas para se "mexer com os padrões", como destaca TPM em seu Mídia kit (TRIP, 2015), mas também por seu caráter apelativo frente ao público. Afinal, ir tão evidentemente contra as propagações vigentes em revistas pode contribuir para a compra do exemplar de TPM. O fato é que a principal matéria da edição, A patrulha chegou lá! (CORTÊZ, 2014, p. 44-49), sugeriria uma liberação ilustrada ainda por uma montagem com inúmeros desenhos e fotos da genitália feminina.

A revista parece, então, estar a anos luz de distância dos séculos 16 e 17, quando as relações sexuais da brasileira "de bem" tinham por justificativa e único fim a procriação e deveriam ser protegidas pela instituição do casamento. Como lembra a autora Mary Del Piore (1993), no século 17, as mulheres deveriam se apresentar fiéis, submissas, recolhidas e, sobretudo, fecundas. Elas tinham que "reproduzir tantos filhos quanto as regras da comunidade exigiam e também satisfazer seus parceiros; sua tarefa mais importante era a procriação, sendo sua sexualidade recreativa gradativamente abandonada" 
(PRIORE, 1993, p. 154). Afinal, as múltiplas gestações, na época, afastavam qualquer possibilidade de erotização das relações sexuais. $\mathrm{Na}$ verdade, enquanto Claudia parece intimar a leitora para se identificar com uma mulher que zela por seus relacionamentos e segue o que é dito por especialistas, TPM intenta ir em uma direção totalmente diferente, chamando a leitora para se identificar com uma mulher despojada, que não seguiria regras, que levaria para a casa uma revista com uma capa, no mínimo, inusitada e fora dos padrões.

Sob alguns aspectos, TPM parece, de fato, distanciar-se das mencionadas edições de Claudia, abordando a temática sexual sem relacioná-la de imediato com questões amorosas e afetivas e problematizando algumas atribuições de gênero. Nesse sentido, a revista da Editora Trip propõe um maior protagonismo à mulher, colocandoa como foco dos debates e não somente a partir da perspectiva de um parceiro. Uma matéria como $A$ patrulha chegou lá (CORTÊZ, 2014, p. 44-49), então, abordando cirurgias estéticas que estão sendo feitas na vulva para "levantar o moral" pode denotar uma consciência feminina sobre o próprio corpo e a sexualidade.

Acrescenta-se ainda que o próprio mote da matéria, a ninfo(ISSN 2238-8060) plastia, como procedimento definido como "redução e/ou preenchimento dos grandes lábios e do volume do púbis, clareamento das mucosas vaginais (que é feito pelo corte das pontas dos lábios) e redução dos clitóris" é capaz de denunciar a complexidade dos códigos de conduta quando se fala em sexualidade feminina. Mais do que isso, à medida em que a apresentação da matéria em questão aponta que essa cirurgia se tornou tendência nos consultórios de cirurgia plástica ao prometer "padronizar vulvas para levantar o moral", reitera-se que, na cultura atual, o corpo da mulher continua a ser definido e codificado como passivo, algo que precisa ser aprimorado para 
merecer o contínuo olhar masculino.

Ora, o fato das brasileiras fazerem do país o campeão do mundo em ninfoplastias, nome das mencionadas intervenções na vulva, registrando 13.682 operações desse tipo em 2013, segundo dados da matéria de TPM, expõe que ainda há uma necessidade exacerbada de agradar os parceiros sexuais. Além disso, como trata ainda a própria matéria, aparências e comportamentos valorizados, diferentemente de outros períodos, agora têm como trampolim a indústria da beleza e a mídia - que inclui os filmes pornográficos -, divulgando à grande massa quais os grandes lábios mais atraentes à medida em que deixa de fora quais não merecem ter destaque. TPM destaca três personagens que passaram pelo mencionado procedimento; duas delas foram claramente influenciadas pelos filmes pornográficos que mostraram vaginas "tão mais bonitas" que as delas.

TPM tem seus méritos ao procurar problematizar a questão, trazendo fontes como as ativistas alemãs Claudia Richarz e Ulrike Zimmermann, que fizeram um documentário sobre a vulva e as intervenções que ela sofre, a pesquisadora e psicanalista Joana Vilhena de Novaes, que fala da intolerância às imperfeições e da banalização das (ISSN 2238-8060) cirurgias plásticas, além de cirurgiões plásticos. A revista chega a alertar para a proximidade entre o direito de ter o corpo que se quer, por meio da cirurgia plástica, e a obrigação de se ter o corpo que se impõe. Assim, questiona os padrões de beleza que vem se tornando verdadeira obsessão das mulheres, não sem o impulso das indústrias do cinema, da moda, dos cosméticos, da publicidade e, por quê não?, também da nova indústria das cirurgias estéticas e dos meios de comunicação.

De qualquer maneira, é necessário pontuar que, ao explicar a ninfoplastia, ao apontar que ela existe e como ela é comum, a revista 


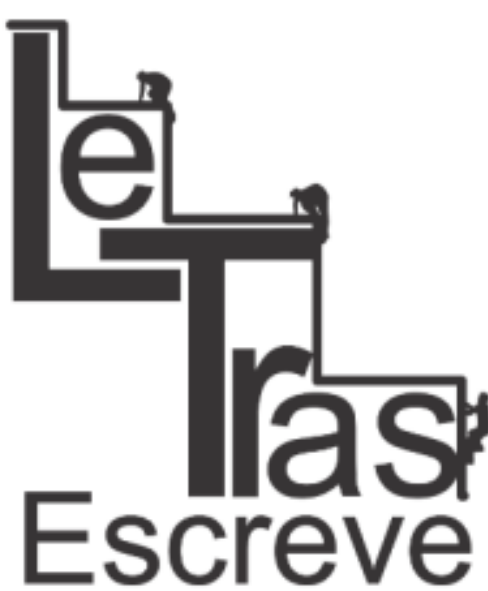

(ISSN 2238-8060)

pode contribuir para a sua propagação. Afinal, uma leitora pode tanto concordar com a pesquisadora, fonte da matéria, que critica esse tipo de técnica, como também, contaminada ainda por uma série de discursos sociais e vivências, pode se identificar com as personagens que escolheram alterar o corpo por meio da cirurgia. Assim, o veículo critica esse tipo de intervenção em alguns momentos, como na conclusão da matéria, remetendo à sugestão de uma jornalista e escritora norte-americana, Natalie Angier, para quem as insatisfeitas com suas vaginas podem simplesmente não raspar os pelos pubianos em vez de ir "para a faca". Ao mesmo tempo, o discurso dá margem para uma certa defesa do procedimento, explicando como é a cirurgia, quanto custa, e elegendo falas como a do cirurgião plástico e membro da Sociedade Brasileira de Cirurgia Plástica Luis Ishida, que diz que esse tipo de cirurgia melhora a autoestima e a vida sexual da muIher.

O veículo pode, então, tanto mostrar como a ninfoplastia é desnecessária, como apontar uma saída para aquelas que estavam insatisfeitas com uma parte do corpo ou até pode despertar um interesse até então inexistente, fazendo emergir uma insatisfação e a necessidade de "correções" estéticas. Por essas vias, ao propor um procedimento para o suposto aprimoramento de uma parte do corpo, TPM não se distancia tanto de Claudia. Isso evidencia a complexidade e transitoriedade dos processos identitários, mas também sinaliza os caminhos por meio dos quais as revistas atingem seu sucesso e conquistam a aceitação de públicos com posturas até controversas.

Além disso, ao mesmo tempo em que TPM procura, em alguns momentos, debater sobre o ímpeto em se adequar às normas estéticas vigentes que são "patrulhas" a padronizar até as genitálias, ela ainda expõe o desejo feminino em agradar o parceiro, como uma das

https://periodicos.unifap.br/index.php/letras

Macapá, v. 7, n. I, Io semestre, 2017. 


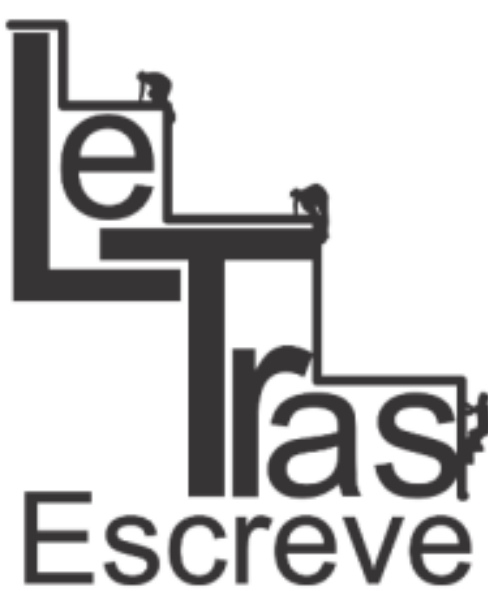

(ISSN 2238-8060)

entrevistadas que buscou a ninfoplastia porque a "cor e o tamanho (dos pequenos e grandes lábios) incomodavam desde que começou a ter as primeiras transas". Enfim, supõe-se, então, que a figura feminina não tenha se desvencilhado por completo da antiga tarefa de adaptar sua existência a partir dos desejos do outro, o que acaba por ainda se manifestar em revista.

Seja como for, os preconceitos quanto à promiscuidade e a aura de periculosidade também continuariam a rondar a categoria "mulheres" na atualidade, como seria tratado em Gosto, não nego (GONZÁLEZ, 2012) ${ }^{8}$, de TPM. A matéria que, segundo a capa, questionaria por quê mulheres sexualmente livres ainda causam polêmica, traria histórias de "periguetes" 9 ". Com ilustrações de pernas femininas e foto de entrevistada em pose descontraída - como a pesquisadora Amnah Asad, que aparece de pernas abertas e um sorriso mostrando a língua -, a matéria dá espaço para personagens anônimas e para celebridades, que falam dos preconceitos que enfrentam por terem tido vários parceiros.

Comparando com os textos elencados até aqui, Gosto, não nego (GONZÁLEZ, 2012) traz mais poder de ação para as mulheres no quesito "sexo", não só destacando personagens que tomam a iniciativa na busca por parceiros sexuais, como também tirando a necessidade de se ter um par, no caso, um homem, para se encontrar o prazer. Embora, infelizmente, a matéria não tenha considerado relações homossexuais e, mais especificamente, lésbicas, a revista, em certa

\footnotetext{
${ }^{8}$ A matéria, que integra a edição temática sobre sexo, traria duas capas, como é tendência em TPM. Uma capa se aproxima mais ao padrão conhecido desses espaços, com a atriz Nanda Costa aparecendo em médio plano. A outra edição de capa inovaria mais. Sem personagens e com um fundo rosa, o destaque seria somente a manchete: "Sim, mulher adora sexo".

${ }^{9}$ Apesar de significar, segundo o Dicionário Aurélio (FERREIRA, 2013), "moça ou mulher que, não tendo namorado, demonstra interesse por qualquer um", o termo periguete não deixa de remeter a "perigo".
}

https://periodicos.unifap.br/index.php/letras

Macapá, v. 7, n. I, Iㅇ semestre, 2017. 


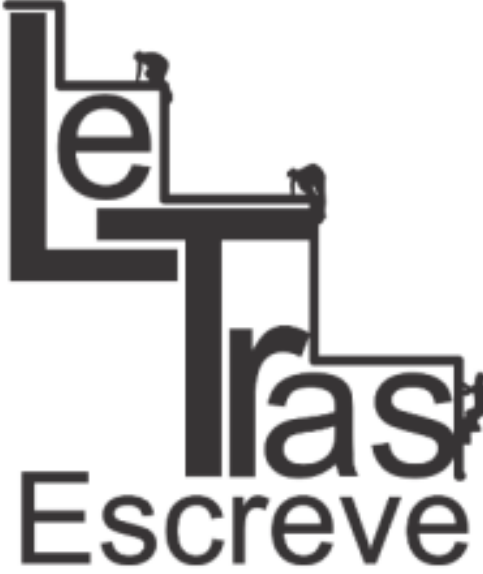

(ISSN 2238-8060)

medida, tira o valor do pênis - comumente concedido nesse tipo de matéria -, destacando a pesquisadora Amnah Asad e a atriz Thalma de Freitas, que falam da importância da masturbação e chegam a recomendar o uso de vibradores.

Ainda assim, voltando a caminhar na direção da lógica patriarcal, a revista não deixa de procurar o porquê de algumas mulheres terem esse perfil, supondo-se, desse modo, que ele seja diferenciado. "Explicação mesmo, só tem uma. 'Eu sou assim', diz a produtora Andrea Fonseca, que há dois anos terminou um casamento de nove e acumula, desde então, dezenas de casos", coloca a revista, em um questionamento bem específico à entrevistada sobre o seu comportamento.

O veículo aponta que a produtora "sai, vê filme abraçada no sofá e faz sexo - muito sexo" com diversos parceiros. Nota-se que a própria ordem de descrição sugere ações consideradas comuns para as mulheres, pela conhecida carga de romantismo de sair, ver filme abraçada no sofá, até que há uma atitude que se supõe inesperada: Andrea faz sexo, "muito" sexo. Ao se pontuar Andrea como um caso especial que merece ser destrinchado, mantém-se a dicotomia entre aquelas mais "certinhas" e as "saidinhas".

A tônica de se buscar por uma justificativa e origem para esse tipo de conduta feminina é reforçada pela própria participação de especialistas, como a psiquiatra Carmita Abdo, que fala de uma abertura inédita quanto à sexualidade feminina no Brasil nos últimos 50 anos. A especialista exemplifica com dados sobre a queda da idade da primeira transa, que passou de 22 para 15 anos, e com o maior envolvimento das mulheres com mais de um parceiro, que, segundo pesquisa, chega a $48 \%$ das jovens entre 18 e 25 anos no século $21^{10}$,

${ }^{10} \mathrm{O}$ índice é uma "novidade relevante", como pontua a matéria, embora ainda seja bem https://periodicos.unifap.br/index.php/letras Macapá, v. 7, n. I, Io semestre, 2017. 


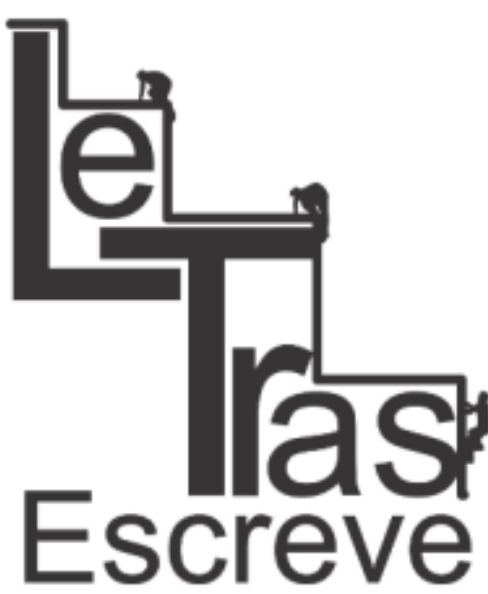

(ISSN 2238-8060)

o que seria impulsionado ainda por mudanças sociais e por fatores como a eclosão das sex shops e dos canais de televisão de conteúdo erótico para mulheres - a análise do que seria essa pornografia voltada para o público feminino certamente já rende pesquisas à parte.

De qualquer forma, a historiadora Mary Del Priore, cuja obra tem sido citada neste trabalho, em Gosto, não nego (GONZÁLEZ, 2012), dá as pistas para o debate: "nos anos 50 se chamava de maçaneta, nos 70 , de piranha e, hoje, é a periguete. Desse modo, ainda que não sejam mais alvo de exclusão social, como poderia ocorrer há algumas décadas e, principalmente, há alguns séculos, a revista fala de uma certa indisposição social com o modo de vida de mulheres que têm vários parceiros", a tal ponto que elas chegam a ouvir que "vão morrer de Aids" e que "negam o seu papel de mulher".

Nota-se que, quando as condutas femininas relacionadas ao sexo não seguem o aceito socialmente, toda a imagem da mulher é questionada, como se, ao "falhar" socialmente em um setor, ela faIhasse em todos os seus papéis atribuídos. Isso também fica evidente na afirmação da modelo Isabeli Fontana, outra personagem da matéria de TPM: "porque sempre falo abertamente que o sexo é essencial na minha vida, as pessoas têm a cara de pau de dizer que sou uma mãe porra-louca". Desse modo, embora, como expôs Hall (2014), haja uma liberdade para o sujeito ter diversas identidades e de forma transitória, em função dos processos sociais atuais, observa-se que a cobrança quanto à determinadas posturas e identificações se mantêm com força quando se trata da figura feminina. Assim, a modelo chegou, inclusive, a se distanciar das redes sociais por estar cansada dos comentários maldosos. Ressalta-se que, apesar da revista estimular o enfrentamento das personagens em relação à pressão social,

menor do que os $70 \%$ dos homens, tão conhecidos por sua inata sexualidade exacerbada que levaria à infidelidade.

https://periodicos.unifap.br/index.php/letras

Macapá, v. 7, n. I, Io semestre, 2017. 


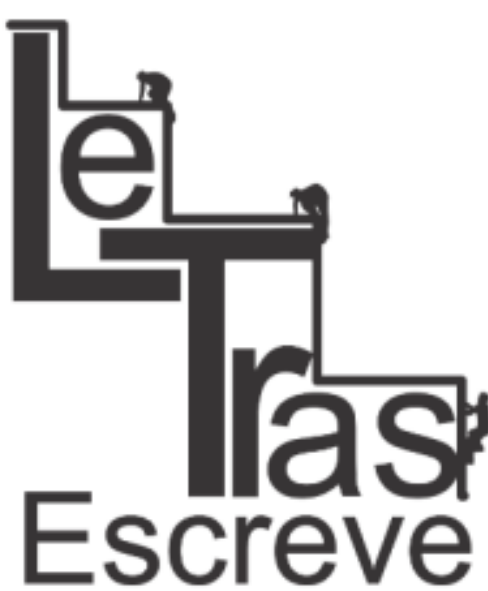

(ISSN 2238-8060)

até uma mulher mais liberal, jovem e respeitada profissionalmente acaba sendo afetada pelas imposições que a cercam, deixando de agir de uma maneira ou de outra ${ }^{11}$.

Seja como for, Gosto, não nego (GONZÁLEZ, 2012), se propõe a destacar depoimentos de cunho libertário, com personagens dizendo, inclusive, que "vão para a cama com alguns que não vão render mais do que sexo", que aprenderam a "se curtir sozinhas" e a se libertar sexualmente, mesmo estando em uma família tradicional. Mais do que isso, a matéria reitera que "a única regra de sexo que vale a pena ser repetida em revista", nas palavras da atriz Thalma de Freitas, "é estar bem consigo mesma para receber alguém dentro de você, e não transar por autoafirmação", o que distancia TPM das "listinhas" de recomendações de Claudia ${ }^{12}$.

A revista também garante méritos quanto à liberação à medida em que as entrevistadas têm espaço não por seu desempenho como mãe, como esposa ou por seu bom desempenho na manutenção do relacionamento duradouro, em atribuições tradicionais, mas por buscarem liberdade quanto à sexualidade. Diante das inúmeras possibilidades de identificação no contexto atual, as leitoras podem, então, se identificar em algum momento com essas personagens, assumindo aquele estilo de vida.

Porém, a matéria de TPM segue reiterando a heterossexualidade - em nenhum momento se fala sob a perspectiva de uma rela-

\footnotetext{
${ }^{11}$ Entre as cobranças que caem sobre os ombros femininos está a pressão social para a mulher conquistar o parceiro, manifestada também em discursos de revista, como se viu, e até em estudos científicos. Assim, a matéria em questão de TPM menciona também pesquisas lideradas por Carmita Abdo no Projeto Sexualidade, do Instituto de Psiquiatria do Hospital das Clínicas de São Paulo, que, ao escutar grupos de mulheres, apontaram para a grande preocupação em agradar o parceiro e para dificuldades em falar sobre os próprios desejos sexuais.

${ }^{12}$ Tais "regras" são, inclusive, satirizadas na coluna da pesquisadora Denise Gallo, Livre $e$ poderosa, que, emendada à Gosto, não nego, trata da intenção de uma mulher em adotar todas as regras propostas em revista, o que pode chegar a inibir o desejo sexual.
}

https://periodicos.unifap.br/index.php/letras

Macapá, v. 7, n. I, Io semestre, 2017. 


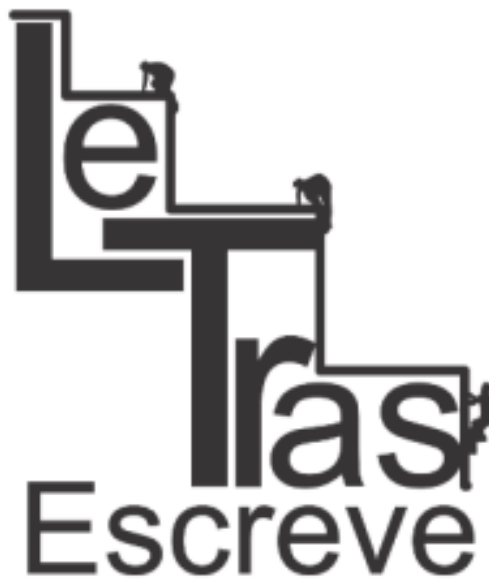

(ISSN 2238-8060)

ção homossexual -, a importância da mediação de profissionais para um melhor cuidado de si e, ainda que de maneira diferenciada em relação à Claudia, não deixa de trabalhar com normas, ao propor a obrigatoriedade do autoconhecimento como sugestão geral. Além disso, é necessário questionar se, em dados momentos, não houve uma inversão de enfoque em relação ao tema proposto na capa. Afinal, ao perguntar o porquê de uma entrevistada ter vários parceiros, ou destacar especialistas falando da mudança de comportamentos na sociedade, do impulso à sexualidade dos meios de comunicação às sex shops, a publicação acaba mais por averiguar porque as muIheres estão sexualmente livres do que por trazer a razão dessas muIheres causarem tanta polêmica, como se supunha na primeira página. Portanto, pode-se admitir que, como neta da "maçaneta" de que falava Priore, na mencionada Gosto, não nego (GONZÁLEZ, 2012), a periguete ainda não perdeu, nem nas páginas de revista, sua carga de perigo.

\section{Considerações finais}

A figura feminina, há séculos, é celebrada por ser capaz de gerar a vida, ao mesmo tempo em que é admitida como um caminho para a perdição. Como bem deixaram claro os posicionamentos da Igreja e do saber médico no período colonial, o que determinaria a chegada a cada um desses dois destinos, da vida e, portanto, da salvação, ou da perdição, seria o aparato de regras, respeitadas ou não, no exercício dessa sexualidade da mulher. Obviamente, os séculos que nos separam da época colonial promoveram mudanças nas concepções quanto à sexualidade e permitiram uma maior liberação do corpo feminino.

https://periodicos.unifap.br/index.php/letras

Macapá, v. 7, n. I, Io semestre, 2017. 
No entanto, determinados papéis de gênero permanecem no acionamento de identidades da mulher pelas revistas. Assim, as publicações falam para a parceira que pretende conquistar o homem, que almeja ter um corpo que agrade, em proposições que não deixam de confluir para a lógica do patriarcado. Aceitar as proposições pode significar manter a leitura e a compra de um exemplar, o que justifica o empenho dos títulos na aplicação das estratégias.

$\mathrm{Na}$ verdade, as temáticas de amor e sexualidade nunca deixaram de ser apontadas como os pilares da matriz identitária feminina, o que se nota também em revistas. Concorda-se com Swain (2014, p. 48-49), para quem a maior liberdade do gênero feminino passa, inclusive, pela desconstrução dessas máximas, reduzindo a importância desses dois fatores. A autora defende, então, uma desmistificação do valor da sexualidade e a desconstrução de seu aparato de urgência, já que, "ninguém morre por não ter sexualidade ativa, mas mulheres morrem por não aceitarem a imposição sexual". No que se refere ao amor, faz-se necessário se desfazer a ideia de que só se existe a partir de olhar e desejo do outro, o que, como se viu, foi tão reforçado nos discursos em revista, das tradicionais listinhas às intervenções na genitália, em fio invisível que nos liga às concepções da era colonial e nos mantém sobre as bases do patriarcado.

Por outro lado, como detalhou Hall (2014, p. 11), atualmente, em função dos processos sociais, a identidade torna-se uma "celebração móvel", sendo formada e transformada continuamente em relação às formas pelas quais se é interpelado nos sistemas culturais. O sujeito se torna fragmentado e os processos de identificação são mais provisórios e problemáticos. Nesse sentido, olhando-se para as revistas Claudia e TPM do século 21, nota-se que, refletindo esse processo, as convocações identitárias não caminham linearmente, 
somente na direção de tradicionais atribuições ao gênero. Há perspectivas diferenciadas, o que se manifesta mesmo no espaço conferido a personagens admitidas como inovadoras, que adotam uma sexualidade mais liberada, por exemplo.

Soma-se a isso o fato de que sempre há a possibilidade de transição entre os papéis identitários. Desse modo, o sujeito pode se identificar, em dado momento, com Claudia, com TPM, ou com nenhuma das duas. Esses percursos pressupõem uma liberdade e uma forma mais reflexiva de vida. Afinal, não há garantias sobre que postura a leitora da revista feminina assumirá amanhã.

\section{Referências}

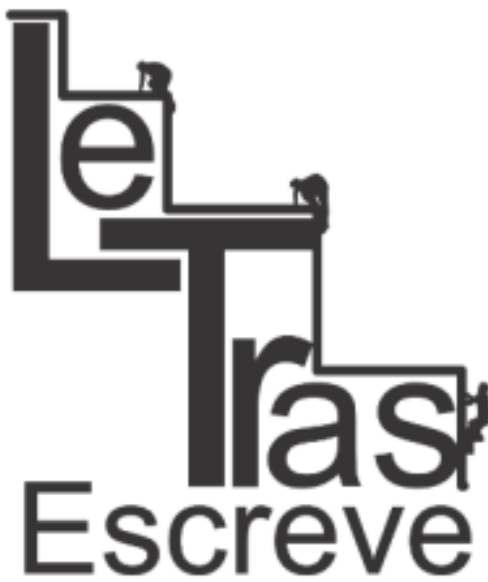

(ISSN 2238-8060)

ABRIL [on-line]. Perfil dos leitores. Fonte dos dados: estudos Marplan. Disponível em: <http://www.publiabril.com.brz. Acesso em 23 nov. 2016.

CLAUDIA. São Paulo: Editora Abril, ano 52, n. 4, abr. 2013. . São Paulo: Editora Abril, ano 53, n. 10, out., 2014.

CORTÊZ, N. A patrulha chegou lá! TPM. São Paulo: Trip Editora, n. 146, set., 2014 (p. 44-49).

COSTA, M. P. Entre o sonho e o consumo: as representações femininas na revista Claudia (1961-1985). Tese (Doutorado) - PósGraduação em História e Sociedade, Universidade Estadual Paulista (Unesp), Assis, 2009, 235p.

CULLER, J. Teoria literária: uma introdução. São Paulo: Beca Produções Culturais, 1999. Trad. Sandra Vasconcelos.

D’ERCOLE, I.; KRANZ, B. "Não basta durar! Tem que ser muito bom". In: CLAUDIA. São Paulo: Editora Abril, ano 53, n.10, out., 2014, p. 178-180. 


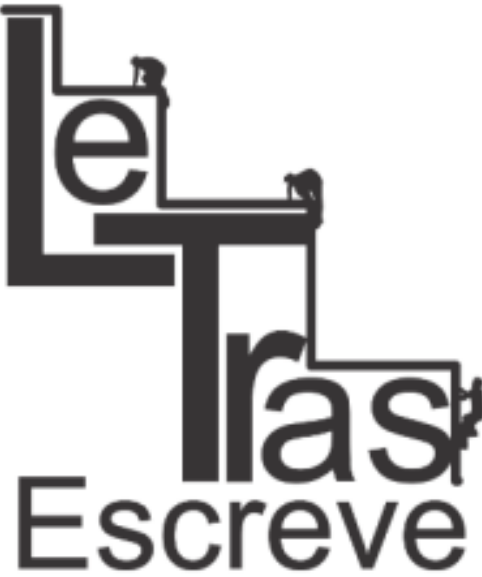

(ISSN 2238-8060)

DINIZ, D. "Perspectivas e articulações de uma pesquisa feminista". In: STEVENS, C.; OLIVEIRA, S. R.; ZANELLO, V. Estudos feministas e de gênero: articulAÇÕES e perspectivas. Florianópolis: Ed. Mulheres, 2014, p. 11-21.

FAUSTO-STERLING, A. Dualismos em duelo. Cadernos Pagu, Campinas, n.2, 2002, p. 9-79.

FERREIRA, A. B. de H. Dicionário Aurélio da língua portuguesa. Curitiba: Positivo, 2013.

FUNCK, S. B. Desafios atuais dos feminismos (p. 22-35). In: STEVENS, C.; OLIVEIRA, S. R.; ZANELLO, V. Estudos feministas e de gênero: articulAÇÕES e perspectivas. Florianópolis: Ed. Mulheres, 2014.

GONZÁLEZ, L. Gosto, não nego. TPM. São Paulo: Trip Editora, n. 124, set., 2012. Disponível em <http://revistatpm.uol.com.br/reporta gens/124/gosto-nao-nego.html . Acesso em 24 ago. 2016.

HALL, S. A identidade cultural na pós-modernidade. Rio de Janeiro: Lamparina, 2014. Trad. Tomaz Tadeu da Silva e Guacira Lopes Louro.

LAURETIS, T. De. A tecnologia do gênero. In: HOLLANDA, H. B. De (Org.). Tendências e impasses: o feminismo como crítica da cultura. Rio de Janeiro: Rocco, 1994, p. 206-241.

MCCLINTOCK, A. Couro imperial: raça, gênero e sexualidade no embate colonial. Campinas: Editora da Unicamp, 2010. Trad. Plínio Dentzien.

STOLCKE, V. "O enigma das intersecções: classe, 'raça', sexo, sexualidade: a formação dos impérios transatlânticos do século XVI e XIX". Revista Estudos Feministas, Florianópolis, v. 14, n.1, jan-abr 2006, p. $15-42$,

PRIORE, M. D. Ao sul do corpo: condição feminina, maternidades e mentalidades no Brasil Colônia. Rio de Janeiro: José Olympio; Brasília, DF: Edunb, 1993. 
SWAIN, T. N. "Por falar em liberdade". In: STEVENS, C.; OLIVEIRA, S. R; ZANELLO, V. Estudos feministas e de gênero: articulAÇÕES e perspectivas. Florianópolis: Ed. Mulheres, 2014, p. 36-51.

TPM. São Paulo: Trip Editora, n. 124, set., 2012. Disponível em <http://revistatpm.uol.com.br/reportagens/124/gosto-nao-nego.ht ml>. Acesso em 24 ago. 2015. . São Paulo: Editora Trip, n. 134, ago., 2013. . São Paulo: Trip Editora, n. 146, set., 2014.

TRIP [on-line]. Mídia kit 2015. Diretoria Comercial, projetos e eventos Ana Paula Wehba. Disponível em <http://www.tripeditora.com. br/wp-content/uploads/2015/04/Trip-Tpm-Mi\%CC\%81dia-Kit2015.pdf> Acesso em 13 ago. 2016.

WOLFF, J. "Recuperando a corporalidade. Feminismo e política do corpo". In: MACEDO, A. G.; RAYNER, F. (Orgs.). Gênero, cultura visual e performance. Braga: Centro de Estudos Humanísticos, Universidade do Minho, 2011, p. 101-120.

ZIEMKIEWICZ, N. Ele só pensa em... dormir! CLAUDIA. São Paulo: Editora Abril, ano 52, n. 4, abr., 2013 (versão para tablet).

Recebido em 04/02/2017

Aceito em 29/03/2017 